\title{
Novel nonresectional posterior leaflet remodeling approach for minimally invasive mitral repair
}

\author{
Bergamo, Italy \\ From the ${ }^{\mathrm{a} C a r d i o v a s c u l a r}$ Department, and Divisions of ${ }^{\mathrm{b}}$ Minimally Invasive and Video-Assisted Cardiac Sur- \\ gery, and ${ }^{\mathrm{c}}$ Cardiac Anesthesia, Cliniche Humanitas Gavazzeni, Bergamo, Italy. \\ Disclosures: Authors have nothing to disclose with regard to commercial support. \\ Received for publication Dec 23, 2016; revisions received March 30, 2017; accepted for publication April 19, \\ 2017; available ahead of print June 9, 2017. \\ Address for reprints: Amedeo Anselmi, MD, PhD, Division of Minimally Invasive and Video-Assisted Cardiac \\ Surgery, Cliniche Humanitas Gavazzeni, Via Mauro Gavazzeni, 21, Bergamo 24125, Italy (E-mail: amedeo. \\ anselmi@alice.it). \\ J Thorac Cardiovasc Surg 2017; 154:1247-9 \\ $0022-5223 / \$ 36.00$ \\ Copyright (C) 2017 by The American Association for Thoracic Surgery \\ http://dx.doi.org/10.1016/j.jtcvs.2017.04.076
}

Alfonso Agnino, MD, ${ }^{\mathrm{a}, \mathrm{b}}$ Matteo Parrinello, $\mathrm{MD},{ }^{\mathrm{c}}$ Paolo Panisi, MD, ${ }^{\mathrm{a}}$ and Amedeo Anselmi, MD, PhD ${ }^{\mathrm{a}, \mathrm{b}}$

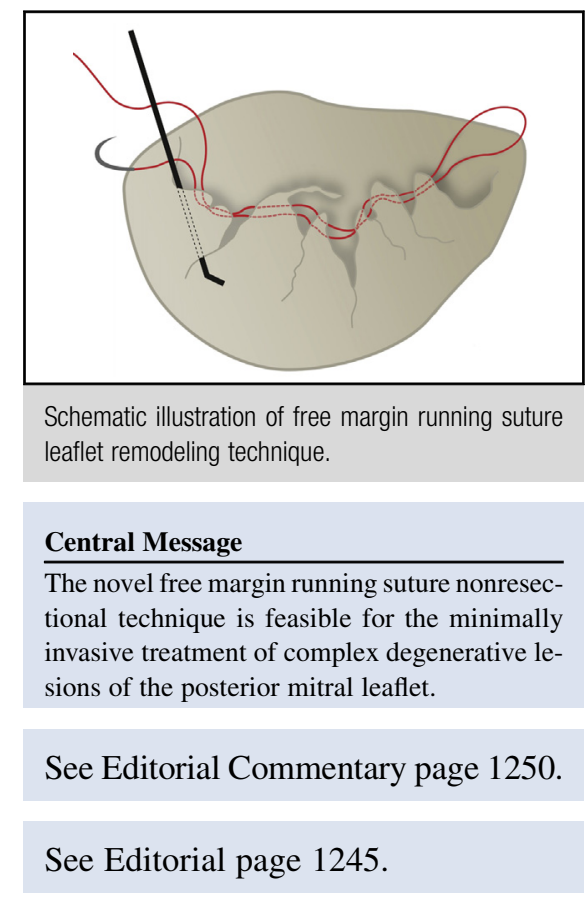

Minimally invasive mitral valve repair increasingly is reproducible, and it is evolving into being the standard-ofcare for the treatment of severe degenerative mitral regurgitation. ${ }^{1}$ Recent years have seen a progressive shift toward a "respect" strategy for the repair of the mitral lesion. $^{2}$ Other groups have proposed a simplified, nonresectional technique based on plication and ventricularization of the prolapsing posterior leaflet segment ${ }^{3}$ as an evolution of the McGoon plication repair. ${ }^{4}$ Although such approach showed very good results, ${ }^{5}$ its feasibility is limited in extensive prolapses, particularly when more than one segment is diseased. Hence, we propose herein a novel nonresectional leaflet remodeling technique for use in minimally invasive mitral repair settings.

\section{OPERATIVE TECHNIQUE}

Proposed criteria for the use of the free margin running suture (FMRS) remodeling technique are large, prolapsing area and flail (mainly if exceeding P2) and redundant tissue,

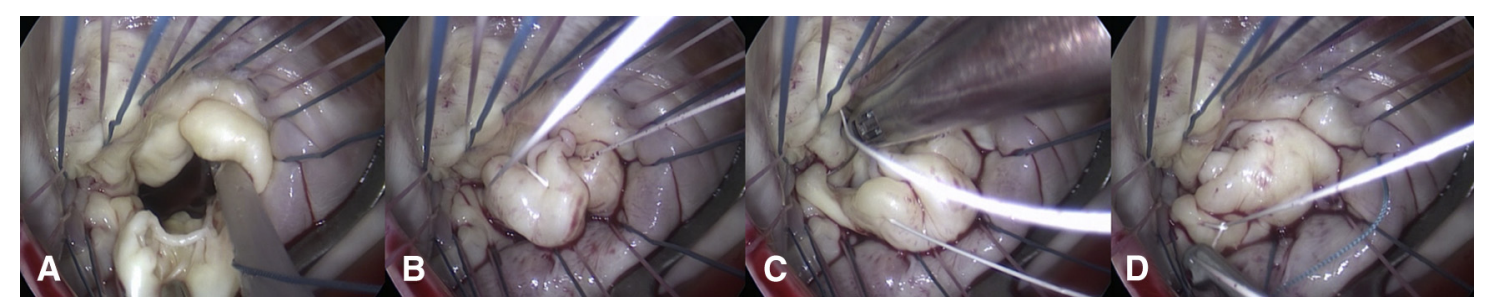

FIGURE 1. Endoscopic view of mitral valve repair through free margin running suture. A, Valve analysis showing extensive prolapse and flail of P2 and P3, normal P1 and anterior leaflet. B, Posterior leaflet remodeling through running suture passed through the free margin of the leaflet, starting at P3. C, The suture is anchored at the free edge of P1. D, The suture is tied at P1. 


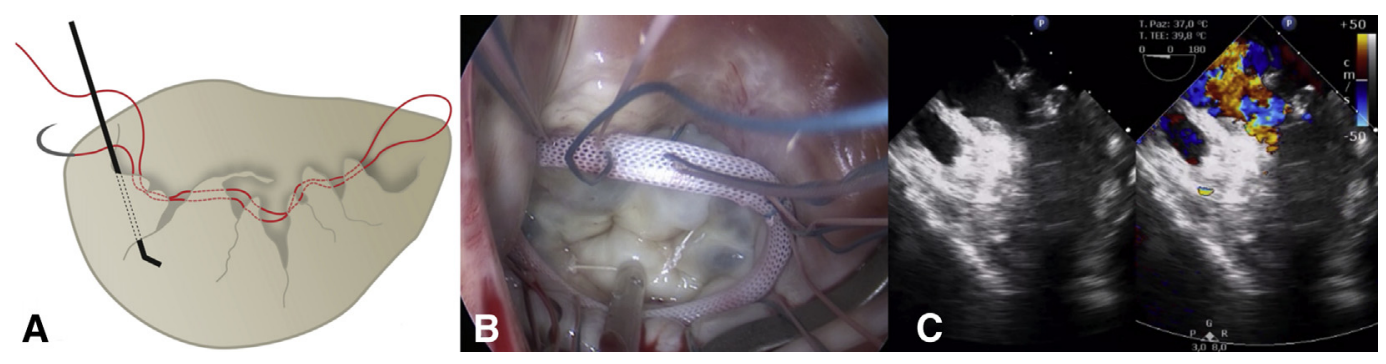

FIGURE 2. A, Schematic illustration of the free margin running suture technique. B, Endoscopic view of mitral valve repair through FMRS. Saline test shows good continence of the valve. Complementary procedure has been performed (stitch closure of a P2-P3 intersegmental defect). C, Intraprocedural transesophageal echocardiography view confirming absence of residual regurgitation.

contemporarily corrected. It is not necessary to implant artificial chordae at the level of the reconstructed segment. At the same time, the excess tissue is redistributed over the length of the posterior leaflet, with ensuing coaptation (Figure 2). For this reason, one additional condition for the application of FMRS is the presence of a sufficient amount of tissue in the segment farthest from the normal one to achieve locally adequate coaptation after remodeling. Complementary procedures are possible for both the posterior leaflet (closure of clefts or intersegmental defects, artificial chordae implantation) and the anterior leaflet. The repair is completed by closed ring annuloplasty.

As it is illustrated in Video 1, this type of repair is associated with preserved mobility of the posterior leaflet and absence of restrictive pattern; such a feature is in common with another previously reported technique for nonresectional leaflet remodeling. ${ }^{6}$ The preservation of the entirety of the posterior leaflet tissue and chordae is likely to determine improved coaptation length with respect to resection-based techniques for the management of the

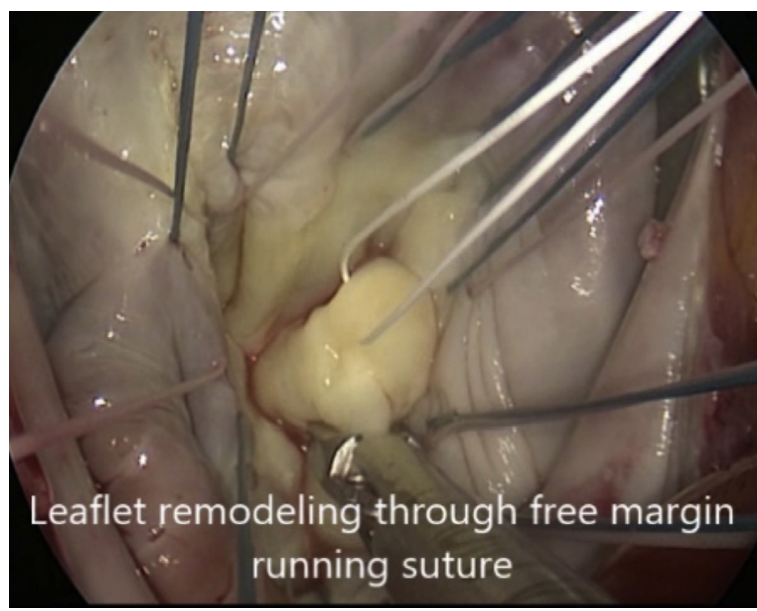

VIDEO 1. Minimally invasive free margin running suture remodeling technique for posterior leaflet remodeling in degenerative disease involving the P2 and P3 segments. Video available at: http://www.jtcvsonline.org/ article/S0022-5223(17)31097-8/addons. same lesion, with potentially reduced propensity to fibrosis of the repaired posterior leaflet in the long term. Similarly, the impact of fibrotic restrictive remodeling in the long term (as observed in cases of failed resection-based repairs) is likely to be minimized.

The applicability of the FMRS technique increases with increasing prolapsing/flail tissue, provided that normal P1 or $\mathrm{P} 3$ is available. Caution must be devoted at preventing systolic anterior motion (SAM); hence, undersized annuloplasty must be avoided. The preservation of a remodeled yet relatively bulky posterior leaflet shifts the systolic coaptation surface toward the anterior leaflet compared with a resection-based technique, which could favor the appearance of SAM in predisposed cases (left ventricular hypertrophy, small left ventricular cavity). Accurate ring sizing is therefore pivotal. Commissural regurgitation needs to be prevented by selecting cases with sufficient amount of leaflet tissue at the commissures. Nonetheless, the FMRS allows straightforward and rapid treatment of complex degenerative posterior leaflet lesions with extensive diseased portions. It is therefore particularly suited for application in minimally invasive surgery, where more complex repair strategies with or without resection would likely entail prolonged cardiopulmonary bypass and aortic clamp times in these patients. Such concept needs nonetheless confirmation through dedicated investigations. Similarly, nonresectional approaches through artificial chordal implantation are associated with prolonged operative times in complex, extensive prolapse. ${ }^{7}$ Such characteristics of the FMRS are of peculiar interest if entirely video-assisted surgery with endo-clamping and minimal skin incision is performed. In the way, FMRS can also be applied through full sternotomy i to facilitate the repair of complex mitral lesions.

Until now, the FMRS technique has been used in 15 cases (10 male, average age $61.3 \pm 6.4$ years, one had undergone a previous coronary bypass surgery; average cardiopulmonary bypass time was $103 \pm 48$ minutes and average aortic clamp time was $79 \pm 35$ minutes). Average postcorrection coaptation length was $10 \pm 3 \mathrm{~mm}$. There were no cases of SAM and no instances of residual 
more-than-mild mitral regurgitation at discharge except one patient. In this case, mild-to-moderate regurgitation $(2+/$ $4+$ ) was disclosed at discharge despite no regurgitation after repair at the intraoperative saline test. This was attributed to rigidity of the basal portion of the P2 segment, with ensuing reduction of coaptation length. At 6-month follow-up, we noted good stability of the repair without cases of recurrent regurgitation or evolution of the regurgitation observed at discharge.

\section{CONCLUSIONS}

We propose a novel nonresectional remodeling plasty for complex degenerative lesion of the posterior mitral leaflet. Initial results are encouraging. The FMRS is suited particularly to facilitate minimally invasive mitral repair; continued follow-up of these patients is ongoing to evaluate durability.

\section{References}

1. Ailawadi G, Agnihotri AK, Mehall JR, Wolfe JA, Hummel BW, Fayers TM, et al Minimally invasive mitral valve surgery I: patient selection, evaluation, and planning. Innovations (Phila). 2016;11:243-50.

2. Perier P, Hohenberger W, Lakew F, Diegeler A. Prolapse of the posterior leaflet: resect or respect. Ann Cardiothorac Surg. 2015;4:273-7.

3. Woo YJ, MacArthur JW Jr. Simplified nonresectional leaflet remodeling mitral valve repair for degenerative mitral regurgitation. J Thorac Cardiovasc Surg. 2012;143:749-53.

4. McGoon DC. Repair of mitral insufficiency due to ruptured chordate tendineae. J Thorac Cardiovasc Surg. 1960;39:357-62.

5. MacArthur JW Jr, Cohen JE, Goldstone AB, Fairman AS, Edwards BB, Hornick MA, et al. Nonresectional single-suture leaflet remodeling for degenerative mitral regurgitation facilitates minimally invasive mitral valve repair. Ann Thorac Surg. 2013;96:1603-6.

6. Shudo Y, Cohen JE, MacArthur JW, Goldstone AB, Hiraoka A, Howard J, et al Non-resectional leaflet remodeling mitral valve repair preserves leaflet mobility: a quantitative echocardiographic analysis of mitral valve configuration. Int $J$ Cardiol. 2015;186:16-8

7. Misfeld M, Borger M, Byrne JG, Chitwood WR, Cohn L, Galloway A, et al Cross-sectional survey on minimally invasive mitral valve surgery. Ann Cardiothorac Surg. 2013;2:733-8. 